\title{
Cation-Modulated Rotary Speed in a Light-Driven Crown Ether Functionalized Molecular Motor
}

\author{
Ruth Dorel, ${ }^{\circledR}$ Carla Miró, Yuchen Wei, Sander J. Wezenberg, ${ }^{\circledR}$ and Ben L. Feringa**(i)
}

Center for Systems Chemistry, Stratingh Institute for Chemistry, Zernike Institute for Advanced Materials, University of Groningen, Nijenborgh 4, 9747 AG Groningen, The Netherlands

\section{Supporting Information}

ABSTRACT: The design and synthesis of an overcrowded-alkene based molecular motor featuring a crown ether integrated in its stator structure has been accomplished. The photostationary state ratios and rotational speed of this motor can be modulated by cation coordination to the crown ether moiety, which can be reversed upon the addition of a competing chelating agent, thus achieving a dynamic control over the rotational behavior of the motor.
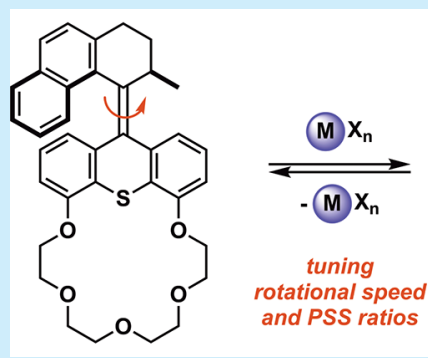

$\mathrm{T}$ he ability to control the dynamics of molecular and supramolecular systems at the nanoscale is ultimately central to the development of the future generation of smart materials as well as to the control of complex biological functions. ${ }^{1}$ In the last decades, both macroscopic machines and biological machinery have inspired the design and synthesis of a number of artificial molecular machines, ${ }^{2}$ which are able to achieve the conversion of chemical, ${ }^{3}$ photochemical, ${ }^{4}$ or electrical stimuli ${ }^{5}$ into mechanical motion.

Overcrowded alkene-based molecular motors, developed in our group, have proven to efficiently undergo controlled unidirectional rotary motion upon irradiation at a certain wavelength and temperature, being the olefinic bond the axle of rotation. $^{6}$ This rotational behavior and the mechanism of operation of a second-generation molecular motor is illustrated in Scheme $1 .^{7}$ The rotation process starts with the photochemical isomerization of the double bond in $(P)$-stable $\mathbf{1}$, which gives rise to an unstable conformation $(M)$-unstable $\mathbf{1}$. Subsequent relaxation of this species through a thermal helix inversion (THI) leads to the energetically favored more stable form after sliding of the upper half over the lower half and concomitant reorientation of the methyl group at the stereogenic center from a pseudoequatorial to a more stable pseudoaxial position. The continuous repetition of photochemical and thermal isomerization steps translates into a $360^{\circ}$ unidirectional rotary motion.

The dynamic control of the rotational speed of molecular motors is one of the contemporary challenges faced in the emerging field of molecular machines. Therefore, the development of strategies for the regulation of the rotary speed of these systems is essential for their implementation as key components in nanodevices. Since the development of the first unidirectional light-driven molecular motor in 1999, ${ }^{\text {6a }}$ much effort has been devoted to the regulation of the rotational frequency, which is typically achieved through structural
Scheme 1. Rotary Cycle of a Light-Driven SecondGeneration Molecular Motor<smiles>O=[N+]([O-])C1CCc2ccc3ccccc3c2C1=C1c2ccccc2Sc2ccccc21</smiles>

$(P)$-stable 1

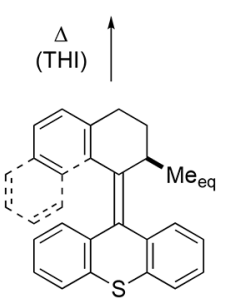

(M)-unstable 1
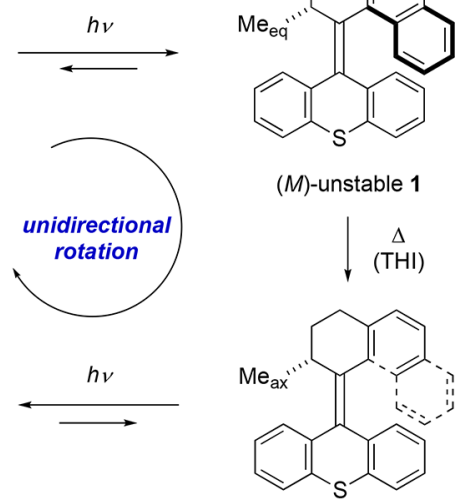

$(P)$-stable 1 modifications that often require tedious synthetic work. ${ }^{8}$ We have reported an alternative approach for the in situ regulation of the rotary speed of a molecular motor that contains a 4,5diazafluorenyl motif relying on the reversible noncovalent binding of different transition metals to the ligand moiety embedded in the motor. ${ }^{9}$ Metal complexation induced the contraction of the diazafluorenyl lower half and concomitantly caused a reduction of the steric hindrance in the fjord region of the motor, which resulted in an enhancement of its rotational speed. Furthermore, we have also recently shown that a molecular motor functionalized with a biphenol moiety can be slowed down through reversible covalent and noncovalent bond formation. ${ }^{10}$

Received: March 26, 2018

Published: June 7, 2018 
In our efforts toward multiresponsive molecular motors, we became intrigued by the possibility of regulating the rotational speed of an overcrowded alkene-based motor by means of supramolecular host-guest interactions. Synthetic macrocyclic polyether hosts have played a key role in the development of supramolecular architectures assembled through noncovalent interactions. ${ }^{11}$ Furthermore, cation-macrocycle interactions have been applied for the regulation of stimuli-responsive systems such as gating membranes ${ }^{12}$ and fluorescent probes ${ }^{13}$ as well as to trigger cation-promoted transformations on metal complexes. ${ }^{14}$ Herein, we report the synthesis, characterization, and isomerization behavior of a second generation molecular motor 2 with a crown ether motif integrated in its lower half (Scheme 2). We also demonstrated that the speed of rotation

Scheme 2. Regulation of the Rotational Speed of 2 by Cation Coordination

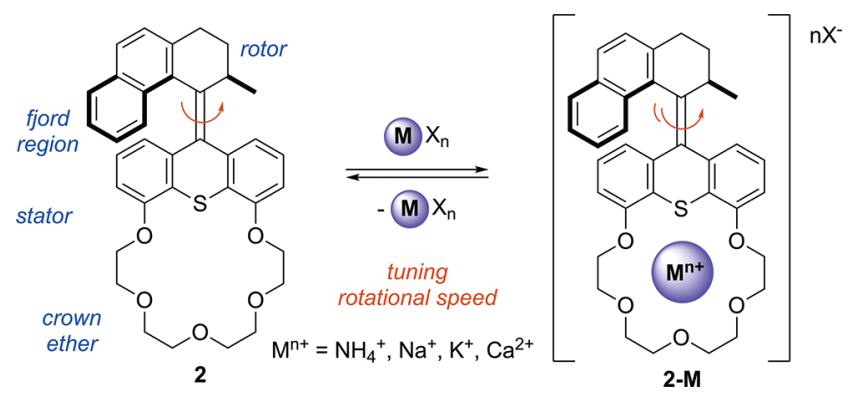

of $\mathbf{2}$ can be dynamically modulated by reversible coordination of simple alkali and earth alkali metal cations to the crown ether moiety.

The synthesis of $\mathbf{2}$ is outlined in Scheme 3. We envisioned that the key transformation in the synthesis of $\mathbf{2}$ would be the Barton-Kellogg diazo-thioketone coupling of the two halves of the motor, which has been extensively used to construct the overcrowded alkene axis in structurally related secondgeneration molecular motors taking advantage of the gradual increase of steric strain throughout the sequence. However, the direct coupling of previously reported hydrazone $4^{15}$ and the thioketone derived from $5^{16}$ proved to be challenging under various reaction conditions typically used in Barton-Kellogg couplings. $^{6 \mathrm{~b}, 17}$ Therefore, an alternative coupling partner 7 was prepared from 5 by initial cleavage of the methyl ethers and acetylation of the resulting free hydroxyl groups in $\mathbf{6}$ (Scheme 3). Treatment of 7 with Lawesson's reagent afforded thioketone 8 in quantitative yield, which was directly coupled with the diazo compound 9 that results from the treatment of $\mathbf{4}$ with $\mathrm{PhI}(\mathrm{OTf})_{2}$. This transformation gave rise to episulfide $\mathbf{1 0}$ in $28 \%$ yield together with $70 \%$ of unreacted 8 , which could be recycled in a subsequent coupling step. Treatment of $\mathbf{1 0}$ with HMPT led to the formation of the desired overcrowded alkene with concomitant partial cleavage of the acetate groups, which was completed by methanolysis of the resulting crude mixture to form 11 in $73 \%$ yield over the two steps. Final etherification of 11 allowed the assembly of the crown ether fragment and therefore gave rise to the target molecular motor 2 .

The photochemical and thermal isomerizations of $\mathbf{2}$ were initially monitored by UV/vis spectroscopy. Irradiation of a solution of 2 in $\mathrm{CH}_{3} \mathrm{CN}$ with $312 \mathrm{~nm}$ light at $20{ }^{\circ} \mathrm{C}$ resulted in a hypsochromic shift of the absorption spectrum with a clear isosbestic point at $\lambda=306 \mathrm{~nm}$ indicative of a unimolecular isomerization process (Figure 1). Subsequent thermal helix
Scheme 3. Synthesis of Motor 2
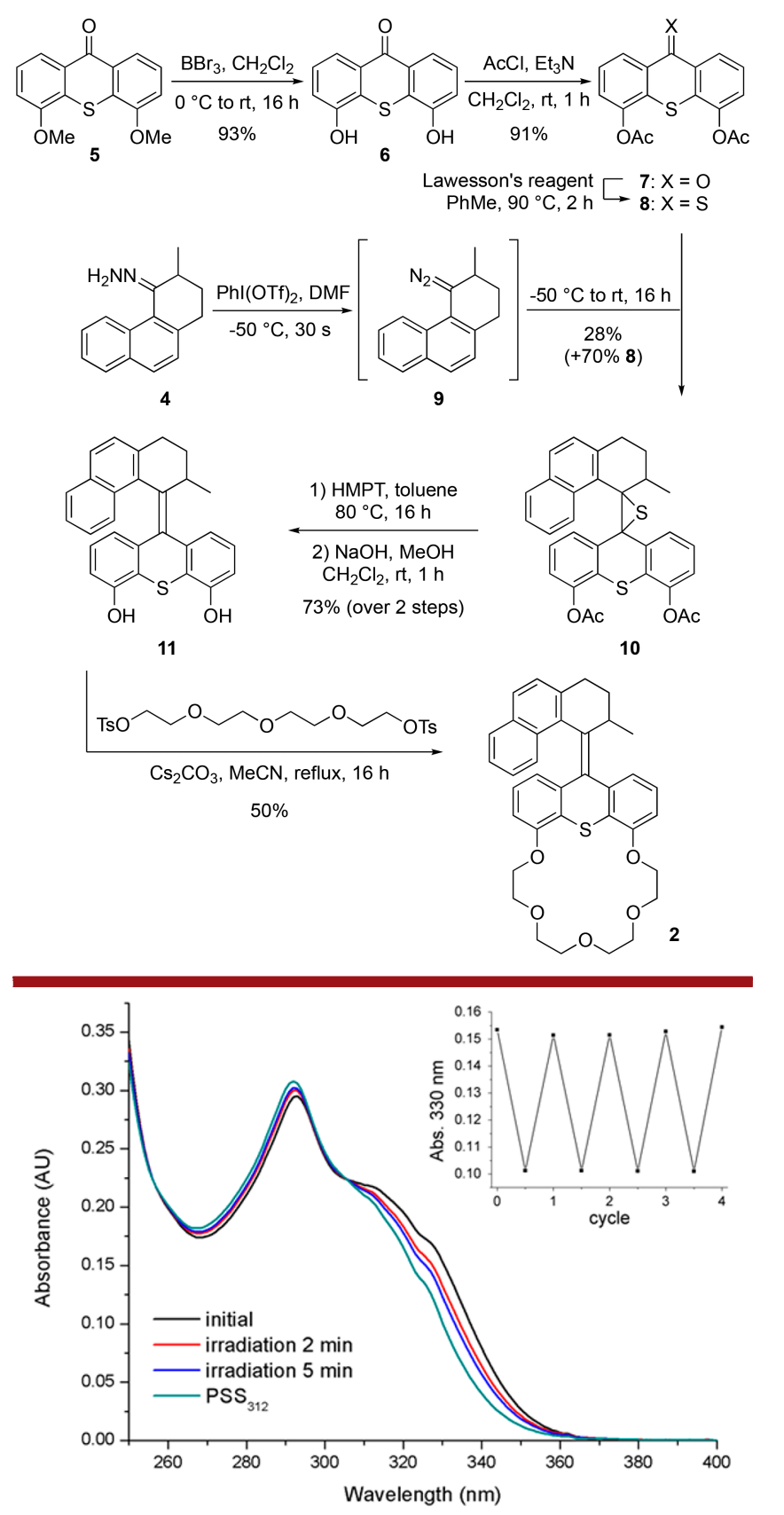

Figure 1. $\mathrm{UV} /$ vis spectra of 2 before and after irradiation $(\lambda=312$ $\mathrm{nm})$ at $20^{\circ} \mathrm{C}$ in degassed $\mathrm{CH}_{3} \mathrm{CN}\left(2 \times 10^{-4} \mathrm{M}\right)$. The inset shows the change in $\mathrm{UV} /$ vis absorption at $\lambda=330 \mathrm{~nm}$ after several irradiation/ warming cycles.

inversion of the metastable species at ambient temperature led to the reestablishment of the original spectrum thus indicating the completion of a $180^{\circ}$ rotation cycle. The irradiationthermal relaxation sequence could be repeated over several cycles on the same motor sample without any signs of fatigue (Figure 1, inset).

The light-induced isomerization process was also analyzed by ${ }^{1} \mathrm{H}$ NMR spectroscopy. After irradiation $(\lambda=312 \mathrm{~nm})$ of a solution of 2 in $\mathrm{CD}_{3} \mathrm{CN}$ at $-40{ }^{\circ} \mathrm{C}$, a $\mathrm{PSS}_{312}$ ratio of stable/ metastable $=65: 35$ was determined by relative integration of the peaks corresponding to the methyl groups at the stereogenic center in both the stable and metastable species. 
This signal is shifted downfield for the metastable isomer, which features the methyl group in a pseudoequatorial position. ${ }^{19}$

Once the rotary cycle of 2 had been established, its cation complexation ability was examined by $\mathrm{UV} /$ vis and ${ }^{1} \mathrm{H} \mathrm{NMR}$ spectroscopy. The cations of choice were ammonium, lithium, sodium, potassium, and calcium, and for this study, we used the corresponding salts with non-coordinating anions hexafluorophosphate $\left(\mathrm{NH}_{4}^{+}, \mathrm{Li}^{+}, \mathrm{Na}^{+}, \mathrm{K}^{+}\right)$and trifluoromethanesulfonate $\left(\mathrm{Ca}^{2+}\right)$. Initial $\mathrm{UV} /$ vis studies revealed that upon addition of an excess of these salts to a solution of 2 in $\mathrm{CH}_{3} \mathrm{CN}$, the corresponding host-guest complexes were formed as evidenced by a change in the UV/vis spectrum for all of the cations examined except for $\mathrm{Li}^{+}{ }^{19}$ These results are in line with those obtained for the parent monothia-18-crown- 6 ether, for which no significant interaction with lithium cation was observed. ${ }^{18}$ Therefore, cations $\mathrm{NH}_{4}^{+}, \mathrm{K}^{+}, \mathrm{Na}^{+}$, and $\mathrm{Ca}^{2+}$, which showed a positive interaction with 2 , were selected for further investigations. The formation of complexes 2-M upon addition of those cations to 2 was also clearly evidenced by ${ }^{1} \mathrm{H}$ NMR. Thus, most of the resonances of $\mathbf{2}$ are downfield shifted in the presence of the cationic species, which becomes particularly evident for the signals corresponding to the crown ether moiety ( 3.5 to $4.5 \mathrm{ppm}$ region), the aromatic protons of the lower half of the motor, and the resonance corresponding to the methyl group at the stereogenic center ( 0.4 to $0.7 \mathrm{ppm}$ region). ${ }^{1} \mathrm{H}$ NMR titration studies conducted by monitoring the shifts of the later signal with increasing amounts of cationic species allowed the determination of the cation-binding affinities of $\mathbf{2}$ (Table 1 ), ${ }^{19}$ which are comparable

Table 1. Binding Constants of 2 with Different Cations in $\mathrm{CD}_{3} \mathrm{CN}$ at $25{ }^{\circ} \mathrm{C}$ and PSS Ratios after Irradiation at $312 \mathrm{~nm}$

\begin{tabular}{crc}
$\mathrm{M}_{x} \mathrm{X}_{y}(\mathbf{2}-\mathbf{M})$ & $K_{\mathrm{a}}\left(\times 10^{3} \mathrm{M}^{-1}\right)^{a}$ & $\mathrm{PSS}_{312}$ \\
none $(\mathbf{2})$ & & $65: 35$ \\
$\mathrm{NH}_{4} \mathrm{PF}_{6}\left(\left[2 \supset \mathrm{NH}_{4}\right]\left[\mathbf{P F}_{6}\right]\right)$ & $0.92 \pm 0.03$ & $92: 8$ \\
$\mathrm{NaPF}_{6}\left([\mathbf{2} \supset \mathbf{N a}]\left[\mathbf{P F}_{6}\right]\right)$ & $1.53 \pm 0.04$ & $>95: 5$ \\
$\mathrm{KPF}_{6}\left([2 \supset \mathbf{K}]\left[\mathbf{P F}_{6}\right]\right)$ & $2.15 \pm 0.09$ & $>95: 5$ \\
$\mathrm{Ca}(\mathrm{OTf})_{2}\left([\mathbf{2} \mathrm{Ca}][\mathbf{O T f}]_{2}\right)$ & $4.03 \pm 0.11$ & $>95: 5$ \\
${ }^{a}$ Determined using BindFit software. & \\
\hline
\end{tabular}

to those of monothia-18-crown- 6 ether with the same cations. ${ }^{18}$ Furthermore, irradiation of a solution of complexes $\mathbf{2}-\mathbf{M}$ in $\mathrm{CD}_{3} \mathrm{CN}$ at $312 \mathrm{~nm}$ and analysis of the resulting mixture by ${ }^{1} \mathrm{H}$ NMR allowed, as in the case of $\mathbf{2}$, for the determination of the PSS $_{312}$ ratios, which were significantly improved with respect to 2 when the cations were bonded to the crown ether moiety.

The thermal isomerization of the photoisomerized metastable species generated after irradiation of $\mathbf{2}$ and $\mathbf{2 - M}$ was studied by UV/vis spectroscopy monitoring the kinetics of the process at 5 different temperatures between 5 and $25{ }^{\circ} \mathrm{C}$ in the presence of an excess of the cationic species in order to ensure full complexation. The kinetic profiles were obtained by following the increase in the absorption at $330 \mathrm{~nm}$, and thus the activation thermodynamic parameters were determined applying the Eyring equation (Table 2). ${ }^{19}$ Notably, the Gibbs free energy of activation for the thermal helix inversion is decreased for complexes 2-M with respect to 2, being the effect more notable for complexes with alkali and alkaline earth cations. Thus, taking into account that the thermal helix inversion is known to be the rate-limiting step in the rotational motion of molecular motors, the speed of rotation of $\mathbf{2}$ could be
Table 2. Selected Thermodynamic Parameters for the Thermal Helix Inversion of 2 and 2-M

\begin{tabular}{lcc} 
& $\Delta^{\ddagger} G\left(20^{\circ} \mathrm{C}\right)\left(\mathrm{kJ} \cdot \mathrm{mol}^{-1}\right)$ & $t_{1 / 2}\left(20{ }^{\circ} \mathrm{C}\right)(\mathrm{min})$ \\
$\mathbf{2}$ & 89.0 & 13.9 \\
{$\left[2 \mathbf{N H}_{4}\right]\left[\mathbf{P F}_{6}\right]$} & 88.8 & 12.4 \\
{$[2 \supset \mathbf{K}]\left[\mathbf{P F}_{6}\right]$} & 88.0 & 9.1 \\
{$[2 \supset \mathbf{N a}]\left[\mathbf{P F}_{6}\right]$} & 87.6 & 7.6 \\
{$[2 \supset \mathbf{C a}][\mathbf{O T f}]_{2}$} & 87.4 & 7.1 \\
\hline
\end{tabular}

modulated by cation coordination obtaining up to double speed of rotation in the presence of $\mathrm{Ca}(\mathrm{OTf})_{2}$ in an acetonitrile solution.

We next examined if the metal coordination could be reversed in the presence of a stronger competing coordinating system in order to prove if we could achieve dynamic control on the rotary speed of 2 . We selected to this aim as a model system the formation of $[2 \supset \mathrm{Ca}][\mathrm{OTf}]_{2}$, for which the strongest effects on the rotational speed had been observed, and studied the complexation and decomplexation event by ${ }^{1} \mathrm{H}$ NMR spectroscopy. ${ }^{19}$ Figure 2 shows the shifts observed in the

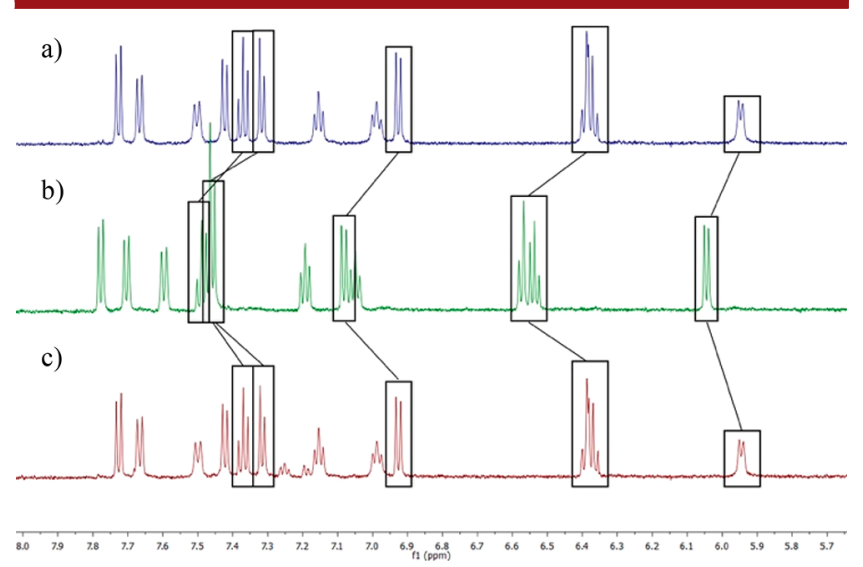

Figure 2. (a) ${ }^{1} \mathrm{H}$ NMR spectrum of $2\left(1.5 \times 10^{-3} \mathrm{M}\right.$ solution in $\mathrm{CD}_{3} \mathrm{CN}$ ). (b) ${ }^{1} \mathrm{H}$ NMR spectrum after the addition of 20 equiv of $\mathrm{Ca}(\mathrm{OTf})_{2}$ to the solution in (a)). (c) ${ }^{1} \mathrm{H}$ NMR spectrum after the addition of 50 equiv crypt-222 to the solution in (b)).

aromatic region of the ${ }^{1} \mathrm{H}$ NMR spectrum. The protons of the lower half of 2, which exhibit a downfield shift upon cation coordination, have been highlighted. To a solution of $\mathbf{2}$ in $\mathrm{CD}_{3} \mathrm{CN}$ (Figure $2 \mathrm{a}$ ) 20 equiv of $\mathrm{Ca}(\mathrm{OTf})_{2}$ were initially added in order to ensure complete formation of 2-Ca (Figure 2b). Subsequent addition of an excess of crypt-222 $(4,7,13,16,21,24-$ hexaoxa-1,10-diazabicyclo[8.8.8] hexacosane) induced the decomplexation of the metal cation from the thiacrown ether moiety and therefore led to the restoration of the original spectrum of 2 (Figure 2c). Furthermore, kinetic studies on the thermal helix inversion of photoisomerized $\mathbf{2}$ in the presence of both $\mathrm{Ca}(\mathrm{OTf})_{2}$ and crypt-222 after irradiation revealed a reestablishment of the rotational speed of the motor prior to cation complexation $\left(\Delta^{\ddagger} \mathrm{G}\left(20^{\circ} \mathrm{C}\right)=89.1 \mathrm{~kJ} \cdot \mathrm{mol}^{-1}, t_{1 / 2}(20\right.$ $\left.{ }^{\circ} \mathrm{C}\right)=14.0 \mathrm{~min}$ ).

In summary, we have developed a novel second-generation molecular motor that features a crown ether moiety integrated in its stator half. Notably, both photochemical and thermal isomerization steps are affected by cation binding, which leads to an increased PSS ratio and an enhanced rotational speed. The cation complexation can be reversed by addition of a 
competing ligand, which translates into restoration of the initial rotational speed of the motor. This work represents a new approach toward the control of the rotational properties of molecular motors and opens up new possibilities in the development of light-driven multiresponsive motors and machines.

\section{ASSOCIATED CONTENT}

\section{S Supporting Information}

The Supporting Information is available free of charge on the ACS Publications website at DOI: 10.1021/acs.orglett.8b00969.

Experimental procedures, ${ }^{1} \mathrm{H}$ and ${ }^{13} \mathrm{C}$ NMR spectra of title compounds, 2D NMR spectra of 2, UV/vis spectra, titration curves, Eyring plot analyses, and PSS determinations (PDF)

\section{AUTHOR INFORMATION}

Corresponding Author

*E-mail: b.l.feringa@rug.nl.

ORCID

Ruth Dorel: 0000-0002-8617-8648

Sander J. Wezenberg: 0000-0001-9192-3393

Ben L. Feringa: 0000-0003-0588-8435

Notes

The authors declare no competing financial interest.

\section{ACKNOWLEDGMENTS}

Financial support from the Ministry of Education, Culture and Science (Gravitation Program 024.001.035), The Netherlands Organization for Scientific Research (NWO-CW, Veni Grant No. 722.014.006 to S.J.W.), the Ramón Areces Foundation (Postdoctoral fellowship to R.D.), and the European Research Council (Advanced Investigator Grant No. 694345 to B.L.F.) are gratefully acknowledged.

\section{REFERENCES}

(1) (a) Molecular Devices and Machines: Concepts and Perspectives for the Nanoworld; Balzani, V., Credi, A., Venturi, M., Eds.; Wiley-VCH: Weinheim, 2008. (b) Molecual Switches, 2nd ed.; Browne, W. R, Feringa, B. L., Eds.; Wiley-VCH: Weinheim, 2011. (c) The Nature of the Mechanical Bond: Form Molecules to Machines; Bruns, C. J.; Stoddart, J. F., Wiley-VCH, 2016. (d) Erbas-Cakmak, S.; Leigh, D. A.; McTernan, C. T.; Nussbaumer, A. L. Chem. Rev. 2015, 115, 1008110206. (e) Kassem, S.; van Leeuwen, T.; Lubbe, A. S.; Wilson, M. R; Feringa, B. L.; Leigh, D. A. Chem. Soc. Rev. 2017, 46, 2592-2621. (f) Pezzato, C.; Cheng, C.; Stoddart, J. F.; Astumian, R. D. Chem. Soc. Rev. 2017, 46, 5491-5507. (g) Lubbe, A. S.; van Leeuwen, T.; Wezenberg, S. J.; Feringa, B. L. Tetrahedron 2017, 73, 4837-4848. (h) Lerch, M. M.; Hansen, M. J.; van Dam, G. M.; Szymanski, W.; Feringa, B. L. Angew. Chem., Int. Ed. 2016, 55, 10978-10999. (i) van Leeuwen, T.; Lubbe, A. S.; Stacko, P.; Wezenberg, S. J.; Feringa, B. L. Nat. Chem. Rev. 2017, 1, 0096.

(2) Selected examples: (a) Kelly, T. R.; De Silva, H.; Silva, R. A. Nature 1999, 401, 150-152. (b) Lewandowski, B.; De Bo, G.; Ward, J. W.; Papmeyer, M.; Kuschel, S.; Aldegunde, M. J.; Gramlich, P. M. E.; Heckmann, D.; Goldup, S. M.; D'Souza, D. M.; Fernandes, A. E.; Leigh, D. A. Science 2013, 339, 189-193. (c) Kelly, T. R.; Bowyer, M. C.; Bhaskar, K. V.; Bebbington, D.; García, A.; Lang, F.; Kim, M. H.; Jette, M. O. J. Am. Chem. Soc. 1994, 116, 3657-3658. (d) Badjic, J. D.; Balzani, V.; Credi, A.; Silvi, S.; Stoddart, J. F. Science 2004, 303, 18451849. (e) Jiménez, M. C.; Dietrich-Buchecker, C.; Sauvage, J.-P.
Angew. Chem., Int. Ed. 2000, 39, 3284-3287. (f) Chen, J.; Leung, F. K. C.; Stuart, M. C. A.; Kajitani, T.; Fukushima, T.; van der Giessen, E.; Feringa, B. L. Nat. Chem. 2018, 10, 132-138. (g) Muraoka, T.; Kinbara, K.; Aida, T. Nature 2006, 440, 512-515.

(3) (a) Fletcher, S. P.; Dumur, F.; Pollard, M. M.; Feringa, B. L. Science 2005, 310, 80-82. (b) Collins, B. S. L.; Kistemaker, J. C. M.; Otten, E.; Feringa, B. L. Nat. Chem. 2016, 8, 860-866. (c) Zhang, Z.; Han, C.; Yu, G.; Huang, F. Chem. Sci. 2012, 3, 3026-3031.

(4) (a) Baroncini, M.; Silvi, S.; Venturi, M.; Credi, A. Angew. Chem., Int. Ed. 2012, 51, 4223-4226. (b) Feringa, B. L. J. Org. Chem. 2007, $72,6635-6652$.

(5) (a) Tierney, H. L.; Murphy, C. J.; Jewell, A. D.; Baber, A. E.; Iski, E. V.; Khodaverdian, H. Y.; McGuire, A. F.; Klebanov, N.; Sykes, E. C. H. Nat. Nanotechnol. 2011, 6, 625-629. (b) Kudernac, T.; Ruangsupapichat, N.; Parschau, M.; Maciá, B.; Katsonis, N.; Harutyunyan, S. R.; Ernst, K.-H.; Feringa, B. L. Nature 2011, 479, $208-211$.

(6) (a) Koumura, N.; Zijlstra, R. W. J.; van Delden, R. A.; Harada, N.; Feringa, B. L. Nature 1999, 401, 152-155. (b) Koumura, N.; Geertsema, E. M.; Meetsma, A.; Feringa, B. L. J. Am. Chem. Soc. 2000, $122,12005-12006$.

(7) The terms stable and unstable used here do not refer to chemical stability but to the thermodynamically favored and the photochemically generated isomer.

(8) (a) Vicario, J.; Meetsma, A.; Feringa, B. L. Chem. Commun. 2005, 5910-5912. (b) Vicario, J.; Walko, M.; Meetsma, A.; Feringa, B. L. J. Am. Chem. Soc. 2006, 128, 5127-5135. (c) Štacko, P.; Kistemaker, J. C. M.; Feringa, B. L. Chem. - Eur. J. 2017, 23, 6643-6653.

(9) (a) Wezenberg, S. J.; Chen, K.-Y.; Feringa, B. L. Angew. Chem., Int. Ed. 2015, 54, 11457-11461. (b) Faulkner, A.; van Leeuwen, T.; Feringa, B. L.; Wezenberg, S. J. J. Am. Chem. Soc. 2016, 138, 1359713603.

(10) van Leeuwen, T.; Danowski, W.; Pizzolato, S. F.; Štacko, P.; Wezenberg, S. J.; Feringa, B. L. Chem. - Eur. J. 2018, 24, 81-84.

(11) (a) Supramolecular Chemistry: Concepts and Perspectives; Lehn, J.M., Wiley-VCH: Weinheim, 2006. (b) Zheng, B.; Wang, F.; Dong, S.; Huang, F. Chem. Soc. Rev. 2012, 41, 1621-1636. (c) Liu, Z.; Nalluri, S. K. M.; Stoddart, J. F. Chem. Soc. Rev. 2017, 46, 2459-2478.

(12) Liu, Z.; Wang, W.; Xie, R.; Ju, X.-J.; Chu, L.-Y. Chem. Soc. Rev. 2016, 45, 460-475.

(13) Li, J.; Yim, D.; Jang, W.-D.; Yoon, J. Chem. Soc. Rev. 2017, 46, 2437-2458.

(14) See, for example: (a) Kita, M. R.; Miller, A. J. M. J. Am. Chem. Soc. 2014, 136, 14519-14529. (b) Ouyang, G.-H.; He, Y.-M.; Li, Y.; Xiang, J.-F.; Fan, Q.-H. Angew. Chem., Int. Ed. 2015, 54, 4334-4337. (c) Kita, M. R; Miller, A. J. M. Angew. Chem., Int. Ed. 2017, 56, 54985502 .

(15) Koumura, N.; Geertsema, E. M.; van Gelder, M. B.; Meetsma, A.; Feringa, B. L. J. Am. Chem. Soc. 2002, 124, 5037-5051.

(16) Pollard, M. M.; ter Wiel, M. J. H.; van Delden, R. A.; Vicario, J.; Koumura, N.; van den Brom, C. R.; Meetsma, A.; Feringa, B. L. Chem. - Eur. J. 2008, 14, 11610-11622.

(17) ter Wiel, M. K. J.; Vicario, J.; Davey, S. G.; Meetsma, A.; Feringa, B. L. Org. Biomol. Chem. 2005, 3, 28-30.

(18) Lamb, J. D.; Izatt, R. M.; Swain, C. S.; Christensen, J. J. J. Am. Chem. Soc. 1980, 102, 475-479.

(19) See the Supporting Information for details.

(20) (a) Thordarson, P. Chem. Soc. Rev. 2011, 40, 1305-1323. (b) Online tools for supramolecular chemistry research and analysis home page. www.supramolecular.org (accessed Dec 19, 2017). 